\title{
A resistência mossoroense nos deslizes da memória e do sentido: uma arqueogenealogia do discurso urbano
}

\author{
The mossorense resistance in the slips from memory and \\ meaning: an archegenealogy of the urban discourse
}

\author{
Edgley Freire TAVARES \\ Universidade do Estado do Rio Grande do Norte (UERN) \\ Francisco Paulo da SILVA \\ Universidade do Estado do Rio Grande do Norte (UERN) \\ Marluce Pereira da SILVA \\ Universidade Federal da Paraíba (UFPB)
}

\begin{abstract}
RESUMO: Na cidade de Mossoró/RN, diversas práticas sustentam um discurso memorialista em torno da resistência desta cidade ao ataque do cangaceiro Lampião, no ano de 1927, produzindo o acontecimento de forma épica e gloriosa. Neste trabalho, analisamos histórica e semiologicamente a atualização dessa memória em materialidades discursivas dispersas pela cidade. Para tanto, assumimos os dispositivos teóricos e metodológicos da análise do discurso para propor uma arqueogenealogia da cidade em suas materialidades discursivas, descrevendo nas regularidades discursivas e nos efeitos de sentido as permanências e as redefinições da memória da resistência.
\end{abstract}

PALAVRAS-CHAVE: Mossoró/RN. Memória da resistência. Arqueogenealogia.

ABSTRACI: In the city of Mossoró/RN, several practices back up a moralist discourse concerning this city's resistance towards tha attack of the bandid Lampião, in the year of 1927, producing an event in an epic and glorious way. Through this work, we have analyzed historically and semiologically the update of that memory in the discursive materialities disperse around the city. For that, we got hold of the discourse analysis's theotethical and methodological devices, in order to propose an archegeneology of the city on its discursive analysis, describing in the discursive regularities and in the meaning effects, the existence and redefinitions of the resistance memory.

KEYWORDS: Mossoró/RN. Resistance memory. Archegeneology.

\section{Introdução}

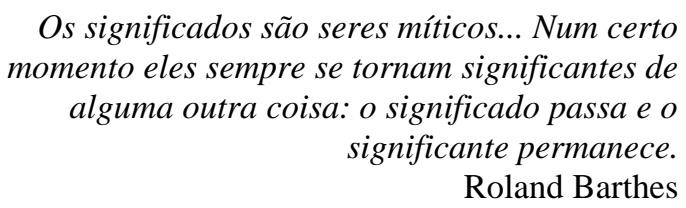

$\mathrm{Na}$ cidade de Mossoró, tornou-se culturalmente hegemônica a memória da passagem do mítico cangaceiro Lampião e do seu bando pelo município, no ano de 1927. Nas últimas décadas, este acontecimento vem sendo construído nos termos de uma resistência heroica e gloriosa da cidade à invasão do grupo de cangaceiros, sendo inúmeras as razões dessa produção memorialística na cultura local, o que despertou nosso interesse pelas razões históricas que possibilitaram esta prática e, sobretudo, as razões de sua remanência em enunciados atuais que circulam em diversos lugares pela cidade. Por isso, 
propomos nesta escrita de análise do discurso a expressão de um voyeur da cidade, interrogando na ordem do discurso urbano mossoroense, as formas que atualizam essa memória da invasão de Lampião à Mossoró.

Para Hall (1997), a cultura é definida como conjunto dos sistemas de significado pelos quais os sujeitos se subjetivam e organizam suas práticas. Nesse aspecto, toda ação social é cultural já que visa sempre a institucionalização de sentidos, fazendo da cultura, pois, uma prática de significação. Aludimos ainda ao conceito de cultura proposto por Geertz (2008), de caráter semiológico, quando o autor pensa a cultura como uma teia de significados tecida pelos homens. Da perspectiva da análise do discurso, descrever as práticas locais que tematizam a resistência em seu funcionamento histórico e semiológico implica problematizar as formas de constituição dessas redes de sentido e a interligação ou correlação que tais "teias" semióticas mantem umas com as outras e com práticas não discursivas na cidade.

Enquanto lugar teórico, assumimos a prática de análise do discurso nas idiossincrasias próprias à maneira brasileira de problematizar o funcionamento histórico das discursividades sincréticas contemporâneas, como propõe Gregolin (2011, p.83), contexto este que impõe "a necessidade de articular à Análise do Discurso uma teoria semiológica". Diante dessa virada histórico e semiológica que marca os trabalhos atuais da $\mathrm{AD}$, propusemos uma arqueogenealogia da cidade de Mossoró, como forma de descrever o funcionamento dessa discursividade da resistência, na tensão e dispersão dos enunciados urbanos que a constituem e em toda a correlação política, cultural e econômica que a possibilitou, estabelecendo, assim, uma delimitação de análise dessa formação discursiva. Com isso, mostraremos na dispersão da memória e dos sentidos como a resistência mossoroense se materializa em prédios públicos, ruas, praças e estabelecimentos comerciais pela cidade, entre a regularidade e a descontinuidade do discurso. Para tanto, o artigo foi organizado em duas partes: primeiramente, analisamos as inscrições urbanas do acontecimento da resistência, evidenciando as especificidades da atualização da memória, tomando a cidade enquanto espacialidade de sentidos. Em seguida, tecemos considerações sobre a análise empreendida, como forma de evidenciar o percurso analítico enquanto uma análise arqueogenealógica do discurso urbano, em torno da passagem do cangaceiro alagoano por esta cidade interiorana do Estado do Rio Grande do Norte.

\section{Pela cidade, travessias do sentido}

No ensaio Semiologia e urbanismo, Barthes (2001) propõe uma semiologia da cidade baseada na significação dos espaços. Enquanto discurso, a cidade se dá a ler em seus sítios de significação, do centro aos outros espaços, espacialidade constituída de funções e oposições geográficas e semânticas. Enquanto linguagem, a cidade é estruturada por tais espaços diferenciais, oposições marcadas e não marcadas de sentido, descritas como unidades no funcionamento urbano. Na proposta barthesiana, uma semiologia da cidade é possível ao colocarmos em causa a relação entre função e sentido, própria a tais espaços diferenciais na cidade. E mais, possível numa convenção do olhar (FOUCAULT, 2007) que considere no gesto de sua descrição que "a cidade é um espaço simbólico particular tendo sua materialidade que produz sua própria forma de significar" (ORLANDI, 2008, p.186). Espacialidade de sentidos só apreendidos no decurso da história e das regras sociais e culturais que marcam o exercício da função enunciativa no espaço urbano.

Em nossa análise do discurso urbano relativa à memória da resistência mossoroense, partimos do conceito foucaultiano de discurso, enquanto "conjunto de 
enunciados que se apoia em um mesmo sistema de formação" (FOUCAULT, 2007, p.122), para categorizar a discursividade urbana, enquanto linguagem inscrita nas regularidades, tensões e contradições da formação dessa memorialística da resistência. Para Barthes (2001), nesse sentido, apreender a semântica do discurso urbano implica assumir uma postura descritiva na qual as materialidades urbanas devem ser lidas em suas condições de produção, em sua historicidade, conferindo às materialidades urbanas o estatuto de enunciado-acontecimento (FOUCAULT, 2007), uma vez que o acontecimento da resistência não preexiste às formas discursivas de sua monumentalização, nem seu funcionamento atual às materialidades dispersas pela cidade. Essa visada aponta para o fato de que o enunciado é unidade e descontinuidade na própria história, sendo singular enquanto acontecimento, aberto a um devir e atravessado por uma memória, o que coloca o problema de seus próprios limites, de seus cortes, de suas transformações, dos modos específicos de sua temporalidade em meio às descontinuidades do tempo (FOUCAULT, 2007).

\subsection{A inscrição urbana do acontecimento: o Memorial}

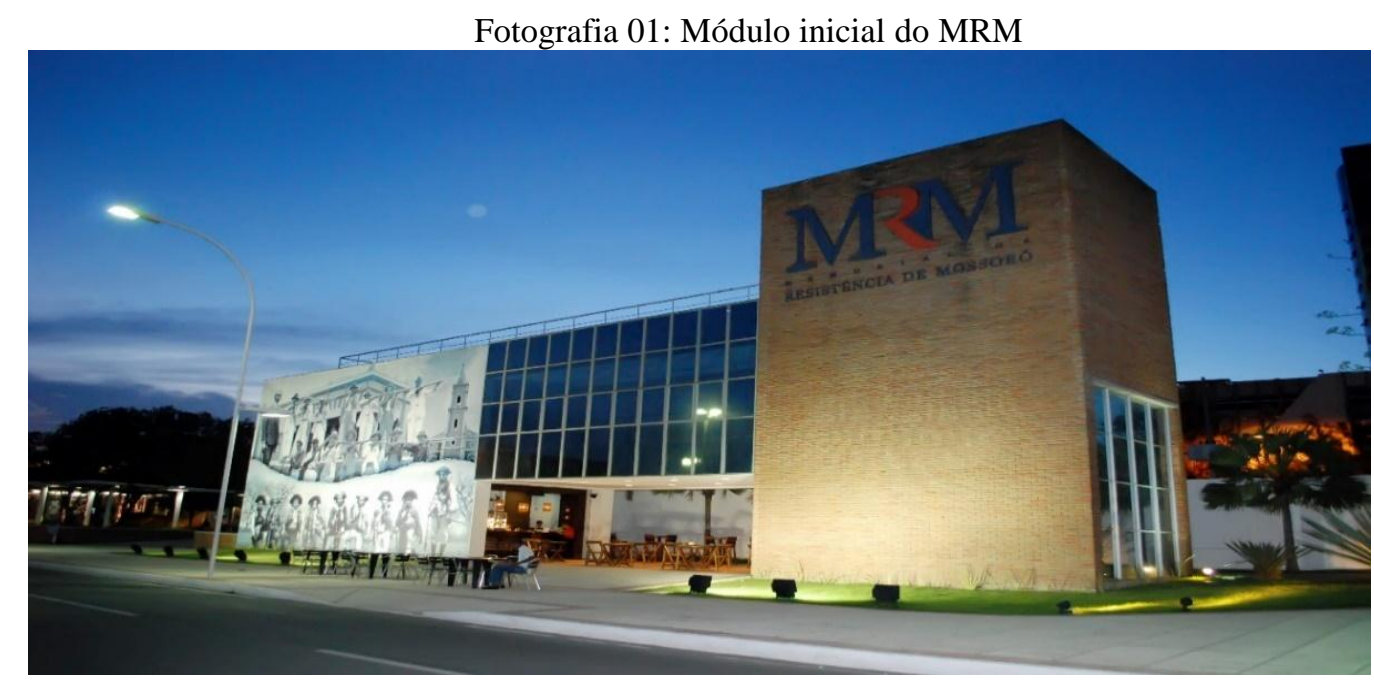

Foto: Edgley Freire Tavares

Localizado no centro da cidade, na Avenida Rio Branco, o Memorial da Resistência de Mossoró ou MRM ergue-se como lugar de memória, servindo de monumento de recordação, materialidade da luta entre mossoroenses e cangaceiros, espécie de acontecimento épico local. Na cidade, essa narrativa é produto de diversos sujeitos e instituições que se engajam na produção discursiva do acontecimento, significando a si próprios ao significar o passado mossoroense em lugares públicos, o que legitima uma ordem do olhar e da lembrança. Nesse sentido, o MRM é um retorno da memória em termos hegemônicos, pois privilegia uma espécie de escrita oficial da história local que é, em grande medida, refém da memória que interessa à elite política e econômica da cidade que viabiliza ou patrocina certas práticas discursivas que a ela interessam. Os enunciados dispostos nesse memorial são uma coleção de fragmentos discursivos perfilados à maneira de um grande mosaico, uma montagem parcial e interessada do passado mossoroense.

Em sua composição arquitetônica, o Memorial "é uma projeção de documentos históricos escritos e imagéticos que são apresentados ao público como material da memória desse feito histórico dos mossoroenses" (TAVARES \& SILVA, 2009, p.23). E mais: esta inscrição urbana deve ser apreendida numa ordem do discurso (FOUCAULT, 2009), 
enquanto tática simbólica que regula a memória e disciplina o olhar. Em meio à paisagem semiológica mossoroense, o MRM é um lugar de memória que representa uma defesa contra aquilo que o tempo ameaça ruir ou aquilo que a história ousa deformar, transformar, pois como propõe Nora (1993, p.13), os lugares de memória são "momentos de história arrancados do movimento da história". Neste espaço público, no centro da cidade, a memória da resistência retorna dando visibilidade a uns e silenciando muitos participantes do evento. Esse movimento de rememoração e apagamento parece ocorrer devido a intenção da política local de inserir a cidade de Mossoró numa espécie de agenda dos lugares que devem ser visitados, enquanto espacialidades marcadas por uma relação com o cangaço e com toda sua estética característica. Por isso, o Memorial funciona, por vezes, como culto à temática do cangaço, constituindo isso um gesto paradoxal, uma vez que o Memorial foi projetado para comemorar a resistência ao cangaço e enaltecer os combatentes mossoroenses.

O Memorial da Resistência consolida uma política oficial da reminiscência explorada pelo poder público em termos de um turismo histórico-cultural.

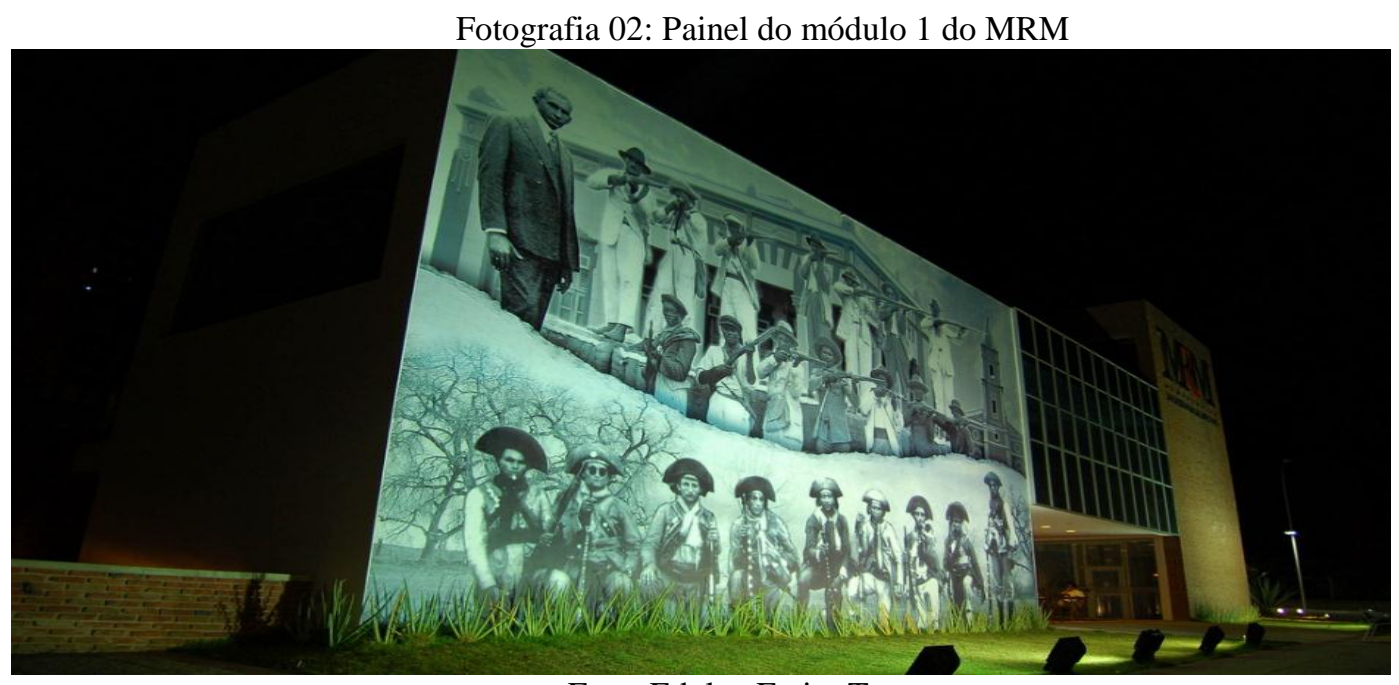

Foto: Edgley Freire Tavares

Este painel exposto na fachada do primeiro módulo recorta a narrativa da resistência. No funcionamento urbano dessa memória, vemos um duplo efeito: se por um lado a cidade, em suas materialidades, atualiza, ao seu modo, essa narrativa, por outro, a própria paisagem urbana se reconfigura por meio dessa prática discursiva. Assim, aquilo que foi erguido não é apenas um monumento arquitetônico, um monumento de linguagens com função turística, e sim, ou antes, um marco simbólico que monumentaliza uma forma de ver e de lembrar o episódio de 1927, dotando-o de sentidos. Neste aspecto, o Memorial é a materialização da memória se transformando em história, pela repetição, pela distribuição ordenada do simbólico no espaço urbano e pelos diversos efeitos aí produzidos, a exemplo das fotografias que compõem o painel. O painel recebe as luzes de toda a avenida e se transforma na síntese de uma mecânica memorialista cujo objetivo é legitimar uma interpretabilidade e certos efeitos de verdade interessados sobre o passado mossoroense. A montagem do painel funciona à maneira de um mosaico fotográfico e regula sentidos ao reproduzir a memória oficial do acontecimento da resistência. Em sua composição, observamos uma perspectiva de dois planos, constituída no esquema from top to bottom, onde se vê fotografias de lugares e pessoas que estão reproduzidas em escala ampliada. De cima para baixo, vemos uma cisão temática no modo como na parte superior perfilam-se os chamados heróis da resistência e, abaixo deles, os cangaceiros, bandidos 
derrotados. O recorte ressoa uma estrutura narrativa produzida ao longo das décadas por meio de várias práticas discursivas na cidade ${ }^{1}$.

Em A câmara clara, Barthes (1984) propõe uma semiologia da fotografia observando dois elementos em co-presença: o studium e o punctum. O primeiro está ligado ao interesse geral que a foto desperta em nós, já o segundo estaria relacionado a certo traço ou aspecto que prende nosso olhar em específico, um detalhe. A esteira do semiólogo francês, diríamos que a montagem de fotografias desperta-nos o interesse de descrevê-la na singularidade de seu funcionamento, enquanto montagem de fragmentos discursivo-visuais em uma formação discursiva, portanto, como materialidade semiológica e histórica do discurso da Resistência. Para nós, há punctum neste mosaico fotográfico no modo como a fotografia de Rodolfo Fernandes é posicionada em relação às demais, no conjunto. Temos aí uma espécie de punctum no enquadramento, já que a foto de Rodolfo Fernandes produz um sentido específico na leitura do painel, estando posta e cuidadosamente projetada à frente dos civis e acima dos bandidos, ocupando lugar de destaque. Descrevendo-o semiologicamente, diríamos ainda que tal pormenor é um indício ou sinal (GINZBURG, 1989) de um efeito de verdade que retorna no painel e serve-se da visibilidade no espaço urbano, a saber: o da tematização da figura do prefeito como líder da resistência mossoroense.

Observando o funcionamento da representação, Barthes (1984) aponta que os referentes aderem às fotos, no sentido de que não podemos dissociar as fotos das pessoas ou dos lugares que nelas vemos projetados. Para o autor, a fotografia supera a si mesma, e a prova de sua arte, do seu modo de ser é justamente essa: "anular-se como medium, não ser mais um signo, mas a coisa em si mesma". (BARTHES, 1984, p.73). Há na foto, segundo Barthes (1984, p.118), um isso foi indiscutível, já que "na fotografia, a presença da coisa (em certo momento passado) jamais é metafórica". Para o autor, o isso foi da foto imprime uma singularidade em relação aos outros sistemas de representação: fazer confundir verdade e realidade em um único gesto do olhar e da leitura. Nenhuma pintura ou gravura, por mais semelhança que carregue, impõe como efeito de sentido, como o faz a foto, que dado referente realmente tivesse existido. Possível por um advento da química, o isso foi da foto é a especificidade desse sistema de representação que joga com seu referente de forma singular, por iluminação, satori ${ }^{2}$, nos termos barthesianos: "a foto é literalmente uma emanação do referente". (BARTHES, 1984, p.121). Partindo desse traço da retórica da fotografia, restaria aos nossos propósitos descrever como tais fotografias e seus referentes são dotados de função e sentido nessa formação discursiva.

As fotos que são perfiladas no painel atendiam a um escopo inicial, não eram antes dali, necessariamente, significantes numa memorialística da resistência. À exceção da fotografia dos entrincheirados, realizada posteriormente ao dia 13 de junho de 1927, dia do

\footnotetext{
${ }^{1}$ Em especial, alguns livros de memorialistas como Raimundo Nonato ([1956] 2011) e Raul Fernandes ([1977] 2007) parecem ter sedimentado no imaginário local, o que chamaríamos de uma escrita oficial do acontecimento da Resistência mossoroense, posto ter sido patrocinada pelo poder público ou gestada entre a elite local, tornando possível uma regularidade discursiva estabelecida a partir de uma estrutura temática amplamente repetida em outras modalidades enunciativas. Os textos destes autores transitam entre a documentação histórica e a narrativa de ficção, legitimando uma interpretabilidade da Resistência, enquanto acontecimento épico e glorioso, a partir de uma narrativa centrada em quatro grandes temas de discurso: a cidade, os mossoroenses, os cangaceiros e o confronto do 13 de junho, objetos discursivos que remanescem em outros gêneros dessa formação discursiva, tais como a literatura de cordel, a mídia e aquilo que denominamos aqui de discurso urbano. Essas formas de expressão repetem a referida estrutura narrativa, mas imprimem formas de retextualização e paráfrase no decurso dessa formação discursiva.

${ }^{2}$ Satori (悟り), termo japonês, empregado pelo autor em romanji e que advém do budismo, significando iluminação, enquanto compreensão, esclarecimento, emanação do sentido.
} 
confronto entre mossoroenses e bandidos, as outras peças deste mosaico significaram antes em outros jogos de memória, outras foram as relações afetivas ou correlações de força que as possibilitaram no tempo-espaço. Assim, dada a fotografia do antigo prefeito, em sua realização segundo seu fotógrafo, o mais razoável seria pensar que, diante da objetiva, Rodolfo Fernandes estivesse posando para um retrato de família, instantâneo que não era significante para o significado de figura pública e líder político de uma resistência cívica armada, efeito este somente possível na consideração dos elementos que sustentam o gesto de leitura aqui realizado, ou seja, somente no decurso, na associação da fotografia com uma memorialística, iniciada na década de $1950^{3}$.

O mesmo se dá com as fotografias da Igreja de São Vicente e do Palácio da Resistência, hoje prédio da administração pública e que fora, na época de 1927, a residência do prefeito da cidade. Postas no painel como plano de fundo para os resistentes mossoroenses, as fotos destes dois locais públicos funcionam produzindo efeitos de sentido que os associa, no presente, às duas principais trincheiras armadas para a defesa da cidade, no ano de 1927. Esse efeito de sentido é produzido alhures, como é possível ler na escrita memorialista de Raul Fernandes, que situa a residência do pai como principal trincheira na cidade, ladeada por outras,

A residência do Prefeito, mansão sem estilo definido, de oitões livres, e altas colunas nas varandas, aparecia imponente, senhorial. Tinha cinco amplos quartos, sala de estar, de visita, e de jantar, afora as demais dependências. Encravada no quarteirão, limitava-se, à direita, com a moradia da esquina, na praça da Igreja São Vicente de Paulo, e, à esquerda, com um bloco de habitações conjugadas. O enorme quintal era dividido ao meio. Na frente situava-se o prédio, e atrás o curral do gado leiteiro e a garagem. Defronte da garagem, passava a linha férrea.

A defesa fora planejada. Poderiam lutar de qualquer lado, sem se afastarem das posições. (FERNANDES, 2007, p.155).

O painel do Memorial é também outra síntese, a de uma estrutura narrativa dada a partir de personagens, cenários e ações, espécie de regularidade discursiva centrada em grande medida no polo temático: mossoroenses resistentes vs cangaceiros bandidos. Produzido décadas atrás, esse polo é um trajeto temático que remanesce no painel com o apelo da linguagem visual, materializado na própria divisão em dois planos que desloca para baixo a representação dos bandidos. Na escrita oficial dessa memória, o cangaceiro é sinônimo de bandido, indivíduo perigoso e sem escrúpulos, agindo por maldade e com requintes de crueldade, ainda que por vezes apareça como sinonímia do exótico, de um modo de vida difícil nos sertões nordestinos. E, como sabemos, historicamente as formas de representar o cangaceiro, e a figura de Lampião é sua expressão máxima, conhecem em outras narrativas outros agenciamentos. Em alguns lugares, a representação de indivíduo perigoso e bandido cede lugar a outras, e em algumas enunciabilidades o cangaceiro aparece como espécie de Robin Hood dos sertões, ou indivíduo que inverte os modos de produção que marcavam a estrutura social da época, centrada, por exemplo, na concentração de terras e de riquezas, quase sempre nas mãos dos chamados coronéis ou políticos das cidades.

\footnotetext{
${ }^{3}$ Na cidade, pesquisadores (FELIPE, 2011; SILVA, 2004) apontam as correlações políticas como fortemente responsáveis pela centralidade da memória da resistência na cultura local. Em especial, estes estudos apontam o peso da família Rosado, enquanto oligarquia que desde a década de 1950 detém o poder político na cidade, viabilizando estratégias para oficializar uma memória do acontecimento do ataque de Lampião que atendesse ao seu projeto político, cultural e identitário.
} 
Talvez por isso mesmo a edição feita no painel analisado nos chame a atenção, pois na parte inferior aquilo que aparece é uma edição de outra fotografia, realizada no dia 16 de junho de 1927, na cidade cearense de Limoeiro do Norte:

Fotografia 03: grupo de Lampião em Limoeiro/CE, em 1927

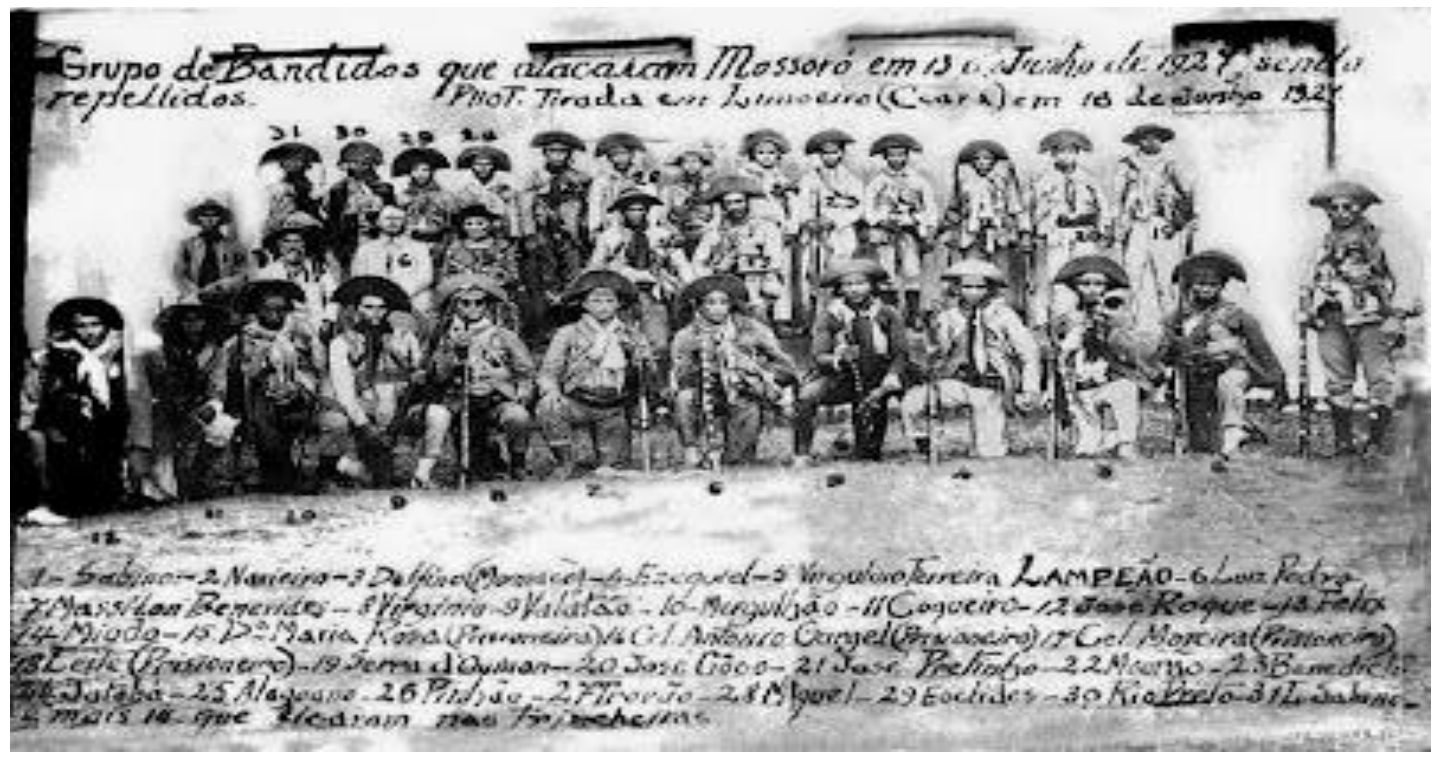

Disponível em: <http://narrativasdobrasil.blogspot.com.br/2012/09/lampiao-em-limoeiro-do-nortece.html>. Acesso em 27 de abril de 2015

Essa fotografia celebra, na ocasião, a entrada triunfante e livre do bando em terras cearenses. Notemos como a edição da fotografia produz sentidos, pois entre o que restou dessa foto no painel e o que dela foi suprimido há um investimento temático, seleção, recorte, numa espécie de ressignificação do referente. Isso porque a fotografia realizada na cidade cearense de Limoeiro do Norte, dois dias após o ataque à Mossoró, produz uma visibilidade do bando bem diferente do modo como os cangaceiros são tematizados na escrita oficial da resistência mossoroense. Na foto do Ceará, apesar do acréscimo impossível de datar que diz "grupo de bandidos que atacou Mossoró em 13 de junho de 1927, sendo repelidos", a pose do bando ilumina-os em sua estética característica, numa formação na qual se vê na fileira de baixo o capitão do bando, Lampião, ladeado pelos principais membros do seu grupo. Diante da objetiva, os cangaceiros não fizeram pose de derrotados, ao contrário, temos na foto outra perspectiva e outro significado, destacando-se a hierarquia e certas especificidades do modo de vida do bando, a exemplo da inserção de alguns dos reféns na foto, indício da tática de sequestro usada pelos cangaceiros.

Por outro lado, o que vemos no painel do Memorial é uma supressão referencial determinada por uma espécie de regulação e controle que faz desaparecer da foto todo o entorno, alguns membros do bando e os reféns. Correlacionando as duas fotos, a edição da foto que fica no Memorial deixa ver apenas os membros mais importantes do grupo, tornando-a outra em relação à foto de Limoeiro. Inclusive, no painel, o entorno da fotografia original do bando some para dar lugar a uma paisagem que faz lembrar o sertão nordestino, imagética regional estabilizada no imaginário nacional (ALBUQUERQUE JR., 2011) por meio de determinadas práticas discursivas e relações de saber e poder. E nesse sentido, a fotografia editada faz dos cangaceiros significantes em outra rede de sentidos, significando enquanto elementos típicos dos sertões, estrangeiros à cidade, invasores. 
Assim, pela perspectiva de Barthes (1984), diríamos que o painel constrói outras relações entre o operator e o spectrum das fotos. Perfiladas no painel, os referentes ou significantes das fotos produzem em nós, spectator, outros sentidos, é outro o retorno do morto de que nos fala o semiólogo francês. No painel, a historicidade dos referentes, tal como pôde ser aprendida pelos fotógrafos em suas condições de produção iniciais, é destituída nos limites e contradições da formação discursiva, pois o projeto gráfico do Memorial produz tais referentes como objetos ou temas em uma memória da resistência, mantendo a oposição vencedores vs vencidos, canônica no discurso da resistência e que o Memorial atualiza reforçando tais sentidos. Assim, a cidade com suas ruas, avenidas, praças e prédios públicos torna-se um espaço de discursivização do acontecimento, ou melhor, espaço de inscrição ou produção do acontecimento, pois aquilo que chega até nós como tendo sido a resistência mossoroense só existe enquanto discurso, não preexiste às práticas de significação.

É nesse sentido que De Certeau (1995) categoriza a cidade como a instância por excelência onde o imaginário se dá a ler e se materializa. De diversas formas, a cidade é o espaço discursivo onde as mitologias são sustentadas. Assim, a cidade é palco ou suporte das idealizações, dos mitos e de todos os aspectos do vivido que só existem no agora enquanto ficções, narrativas de certas ausências:

As mitologias revelam aquilo em que não se ousa mais acreditar e que por isso se busca "em imagem", e muitas vezes aquilo que somente a ficção oferece. Elas enganam simultaneamente a fome e a ação. Elas traem ao mesmo tempo uma recusa a perder e uma recusa a agir. Desse modo, muitas das palavras e imagens narram uma perda e uma impotência, isto é, exatamente o contrário daquilo que elas prodigalizam. (DE CERTEAU, 1995, p.44).

Uma mitologia da resistência mossoroense ao ataque de Lampião se materializa pela cidade, por meio do enunciável, como algo próprio daquilo que está visível no presente (DELEUZE, 2005). É da perspectiva barthesiana que propomos pensar a resistência como mito, como linguagem sincrética, como discursividade que articula formas e funcionamentos diversos, verbais e não verbais (BARTHES, 2001). Nesta análise, selecionamos apenas as materialidades urbanas, lendo-as em sua estrutura e funcionamento (PECHEUX, 2008; FOUCAULT, 2007, 2009; SARGENTINI, 2011), descrevendo-as como enunciados que se constituem na predominância da linguagem imagética, visual ou icônica, reflexo de uma cultura centrada na profusão de imagens e de uma estratégia de inscrição urbana que busca captar o olhar em movimento. Analisamos a resistência como mito, tal como propõe Albuquerque Jr. (2013, p.25), que categoriza o mito como forma de significar entre o enunciável e o visível, significação que produz saberes e objetos, pois acima de tudo, "o mito é uma das formas de transformar o real em discurso, e como esta transformação é histórica, os mitos são falas produzidas na e pela história". Assim, a análise do discurso da resistência em sua inscrição urbana partiu da noção foucaultiana de enunciado (FOUCAULT, 2007), apreendido histórica e semiologicamente, em sua raridade e domínio associado, nas formas específicas de seu acúmulo e remanência, unidade de descrição da gênese e das transformações discursivas, um ponto de partida para uma postura analítica, como lembrou Rago (1995, p.71), que deve estar "preocupada não mais em revelar e explicar o real, mas em desconstruí-lo enquanto discurso".

\subsection{A inscrição urbana do acontecimento: outros espaços}


Nessa paisagem semiológica mossoroense, constituída em diferentes espaços, vemos formas de significação heterogêneas. Como mostra Orlandi (2004), a cidade é organização, uma injunção histórica e simbólica a trajetos, a repartições e a diferenças de sentido que se dão na falha, na contradição, ou nos termos que coloca a autora, na própria desorganização, pois a cidade é uma linguagem desordenada, espaço para "incidência de novos processos de significação que perturbam ao mesmo tempo a ordem do discurso e a organização social". (ORLANDI, 2004, p.63). Enquanto espaço simbólico, a cidade é a escrita de certas práticas subjetivas, modalidades enunciativas que inscrevem no corpo da cidade as próprias singularidades dos lugares sociais de onde emanam os sentidos sobre os mitos, temas e representações que ganham corpo no corpo da cidade. O discurso urbano, como propõe Orlandi (2004), serve de indício para lermos a própria divisão social, pois sendo o consenso algo imaginário, "o discurso social não é homogêneo dando lugar a diferentes movimentos de discurso que se cruzam" (ORLANDI, 2004, p.63), diríamos, na paisagem semiológica urbana, espacialidade de sentidos que marca essa tensão entre organização e desorganização. É por meio dessa tensão que podemos entender a correlação entre os diferentes espaços que constituem a cidade de Mossoró e inscrevem o acontecimento da resistência.

Se o MRM ergue-se no centro da cidade e legitima uma memória que atende a um projeto político e turístico do poder público local, em contrapartida, um tour pela cidade revela outros retornos dessa memória, evidenciando a cidade como instância de dispersão e transformação dos enunciados.

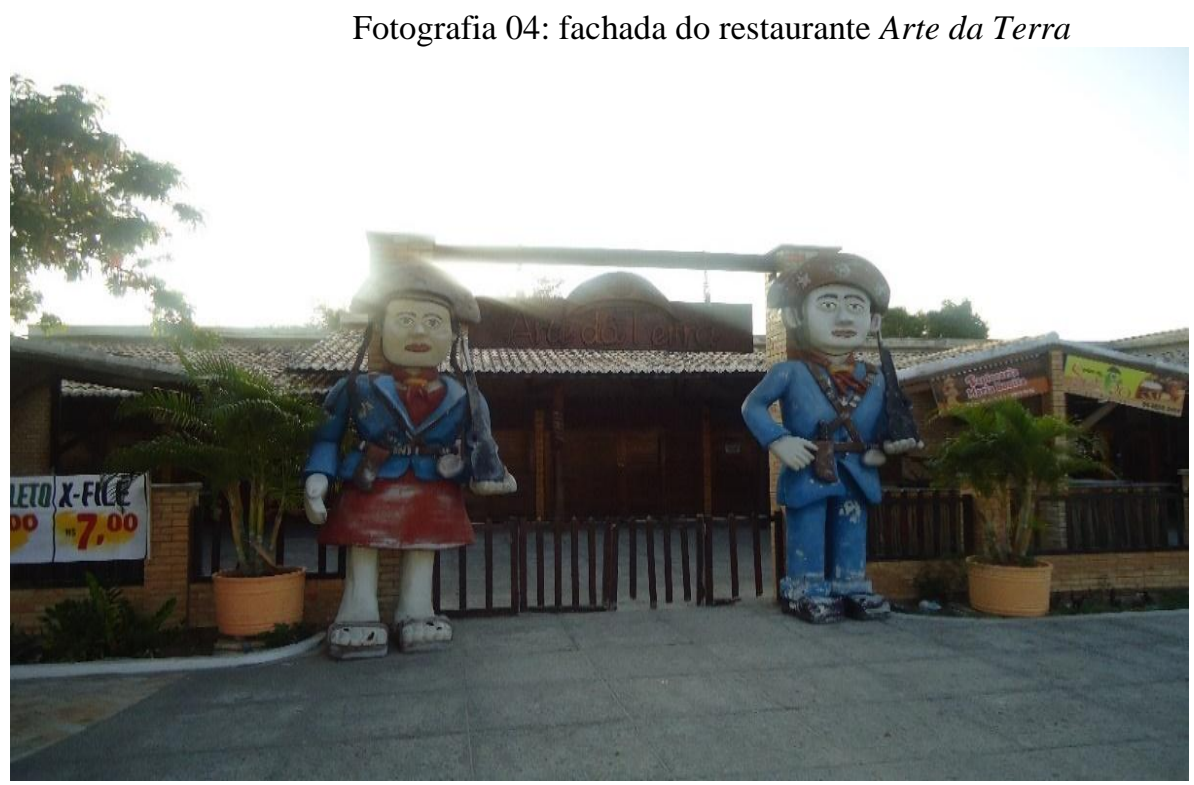

Foto: Edgley Freire Tavares

A fachada de um tradicional restaurante local materializa o modo como a memória da resistência atravessa práticas heterogêneas na cidade. Ou melhor, dá sinais de certas inversões e deslocamentos, próprios da desordem do discurso, tornando possível que uma memória da luta entre mossoroenses e cangaceiros possa deslocar para uma discursividade em torno do cangaço, enquanto tradição na cidade. Essa inversão possibilita que o cangaceiro seja tematizado diferentemente, sendo um significante para outros efeitos de sentido, deslocando-o da ideia de inimigo da cidade, tal como é recorrente na narrativa hegemônica e oficial da resistência e o transforma em símbolo turístico, espécie de 
metonímia de uma suposta identidade cultural local, hoje possível em um novo regime de enunciabilidade no qual o cangaceiro deixa de representar apenas o bandido e mal social para ser também elemento típico da cidade de Mossoró.

Como efeito, a cidade de Mossoró é constituída em uma espacialidade regional, que se produz em torno do pertencimento a uma imagética nordestina, da qual fazem parte o cangaço e sua estética. Possíveis no decurso da narrativa da resistência, algumas materialidades pela cidade atualizam um discurso regionalista, do tipicamente nordestino, prática que, segundo Albuquerque Jr. (2011), resultou na estabilização de certos saberes ou representações e fez com que temas como o coronelismo, o religioso, o cangaço e a seca se tornassem objetos de discurso para sustentar fabulações de uma nordestinidade forjada discursivamente nas tramas da história.

Esse deslocamento temático é um deslize possível por meio de uma série de dispositivos culturais, turísticos e econômicos que transforma os sítios da cidade em lugares de memória. Os temas da resistência e do cangaço, como seu correlato maior, funcionam discursivamente como tradições, tática simbólica que faz "os sujeitos do presente se reconhecerem nos fatos do passado" (ALBUQUERQUE JR., 2011, p.93), fazendo dos espaços da cidade pontos de produção e dispersão da memória em torno da passagem do cangaço pelo Estado do Rio Grande do Norte. Nesse sentido, haveria uma espécie de domesticação do cangaceiro, em um regime de enunciabilidade que autoriza a recorrência de outras formas de representá-lo, como é possível ver também em outro painel, encontrado em um supermercado da cidade.

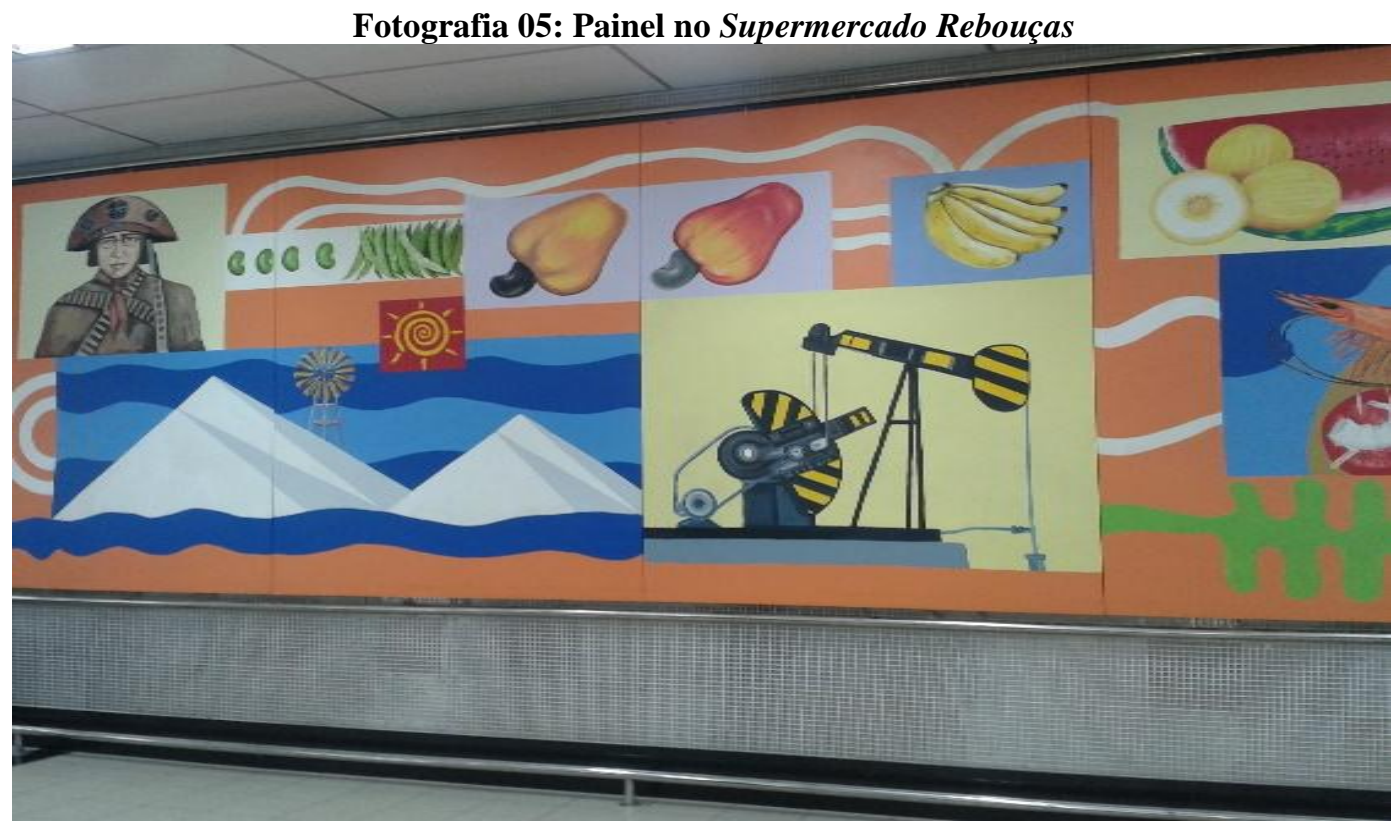

Foto: Edgley Freire Tavares

Este painel decorativo funciona servindo de sinal ou indício semiológico de que a resistência e, por contiguidade semântica, o cangaço, são significantes da cidade, do seu passado e do modo como a cidade é dada a ver, em suas potencialidades e particularidades. Aqui, é possível ler a centralidade da memória e o seu atravessamento em meio a outros quadros de referência, já que a fotografia mostra o cangaceiro, um elemento estruturante do discurso da resistência, funcionando enquanto representação conjugada naquilo que parecem ser elementos ou produtos típicos da cidade. Na fotografia deste painel, o cangaceiro é um ponto específico, fragmento de uma fala mítica que não pode ser 
silenciada, significante de uma memória coletiva gestada e controlada por diversos grupos sociais. Nesta materialidade, enquanto enunciado de uma formação discursiva, o tema do cangaceiro, em meio a outros como o sal, o petróleo e os produtos típicos da geografia e da culinária mossoroenses, torna-se, como propõe Pollak (1989), ponto de referência na memória social. Nesse sentido, a arqueogenealogia busca as correlações e as modalidades enunciativas responsáveis por dotar de duração e relativa estabilidade a memória da resistência na cidade e, assim, o analista do discurso desconstrói memórias, pois descreve os "processos e atores que intervém no trabalho de constituição e formalização das memórias" (POLLAK, 1989, p.04), como forma de compreendê-las em seu funcionamento discursivo. $\mathrm{Ou}$, mais especificamente, cabe ao analista do discurso, como propôs Pêcheux (2011), colocar em causa o estatuto social da memória em seu funcionamento discursivo, a partir da produção, circulação e interpretação de práticas discursivas que põem em jogo determinadas imagens do passado. Vista assim, a memória não é estudada pelo linguista do discurso em sua existência psíquica ou psicológica, mas como um conjunto complexo "constituído por séries de tecidos de índices legíveis, constituindo um corpus sóciohistórico de traços" (PÊCHEUX, 2011, p.142).

Há jogos de repetição e diferença no modo como a memória da resistência se atualiza no espaço urbano da cidade. Para Gregolin (2011), devemos analisar essa atualização da memória por meio da própria opacidade do discurso, interrogando as condições históricas que possibilitaram a canonização de certos aspectos simbólicos. Conforme a autora, diversos agenciamentos e técnicas fazem com que certos acontecimentos retornem com muita força na memória social e, em contrapartida, outros acontecimentos sejam apagados, não enunciados, de modo que estes não possuam nem status e nem função na manutenção de uma certa ordem do discurso. Em outras palavras, o funcionamento histórico e semiológico do discurso se dá numa tensão entre a memória e o esquecimento.

Vejamos como a autora sintetiza a questão:

Por que determinados acontecimentos escapam à inscrição e não entram para a história e são, pelo contrário, apagados? Deriva desse movimento pendular toda a discussão sobre a memória e esquecimento, sobre a dialética entre a rememoração de determinados acontecimentos e o apagamento de outros. $\mathrm{O}$ acontecimento se dá em um momento singular, mas a sua essência se encontrará para sempre na própria estrutura do objeto cultural que o representará. Isso está lá, nessa forma, nessa materialidade que ele adquire. Ele se tornará documento histórico e monumento de recordação. Ele vai se inscrever em uma materialidade, em uma forma, e estará à disposição dos futuros aparecimentos. Tanto há uma memória para o passado como há uma memória para o futuro, pois um acontecimento discursivo abre sempre a possibilidade do seu retorno. (GREGOLIN, 2011, p.90-91).

É nesse jogo entre fazer lembrar e fazer esquecer que consideramos o estatuto destas materialidades discursivas urbanas. Este jogo se marca nos movimentos do enunciado, como mostrou Foucault (2007), já que o enunciado o é por sua função e pelo lugar que ocupa entre outras práticas, discursivas ou não, em um domínio associado. Na cidade de Mossoró, lemos regimes enunciativos diversos que autorizam, regulam e refratam as formas e os sentidos de uma memória da resistência. Na década de cinquenta, uma prática de reminiscência se inicia com a publicação de alguns escritos memorialistas com o escopo definido de lapidar uma espécie de memória oficial sobre o passado 
mossoroense que em grande medida fosse a memória dos grandes feitos dos líderes políticos, econômicos e religiosos locais. E isso, ocorreu em grande medida por meio da criação de espécies de centrais de distribuição de sentidos na cidade, a exemplo da criação de uma gráfica, ou da gráfica Coleção mossoroense, e também, a criação de um museu e de uma biblioteca pública, aparelhagem que fora e ainda é, imprescindível na manutenção de certo imaginário local relativo ao acontecimento da resistência, escrito enquanto algo heroico e símbolo da bravura do povo local e da liderança imaculada de seus líderes. É este o efeito de sentido que mais se acumula em práticas na cidade, a exemplo do Memorial da Resistência Mossoroense, enquanto lugar de memória que faz ressonar uma narrativa na qual os bravos e heroicos mossoroenses vencem os facínoras do cangaço, liderados, sobretudo, pela figura do prefeito à época, idealizado nessa narrativa como tendo sido o grande mentor, articulador e responsável pela defesa da cidade.

Contudo, nossa observação da materialização dessa narrativa na cidade encontrou outras formas de acúmulo de enunciados, a exemplo da iconografia do cangaceiro que retorna diferentemente em estabelecimentos econômicos para servir de marionete no discurso de promoção da cidade, produzindo o urbano mossoroense enquanto espacialidade regionalista. Observamos também que a própria ideia de resistente varia e se transforma em enunciados atuais na publicidade, na literatura de cordel ou mesmo em peças teatrais encenadas periodicamente na cidade. Ainda assim, mesmo no deslize, na descontinuidade e nas rupturas semânticas, há uma regularidade temática, uma estrutura temática, como dissemos, algo que autoriza, inclusive, novas modalidades enunciativas que fundem a memória da resistência a outras, tornando possível o decurso e a ampliação dessa memorialística para atender a outros objetivos e pretensões do presente.

Em outro espaço da cidade, numa praça onde ocorre a prática de skate, encontramos a ruptura com os sentidos hegemônicos da Resistência.

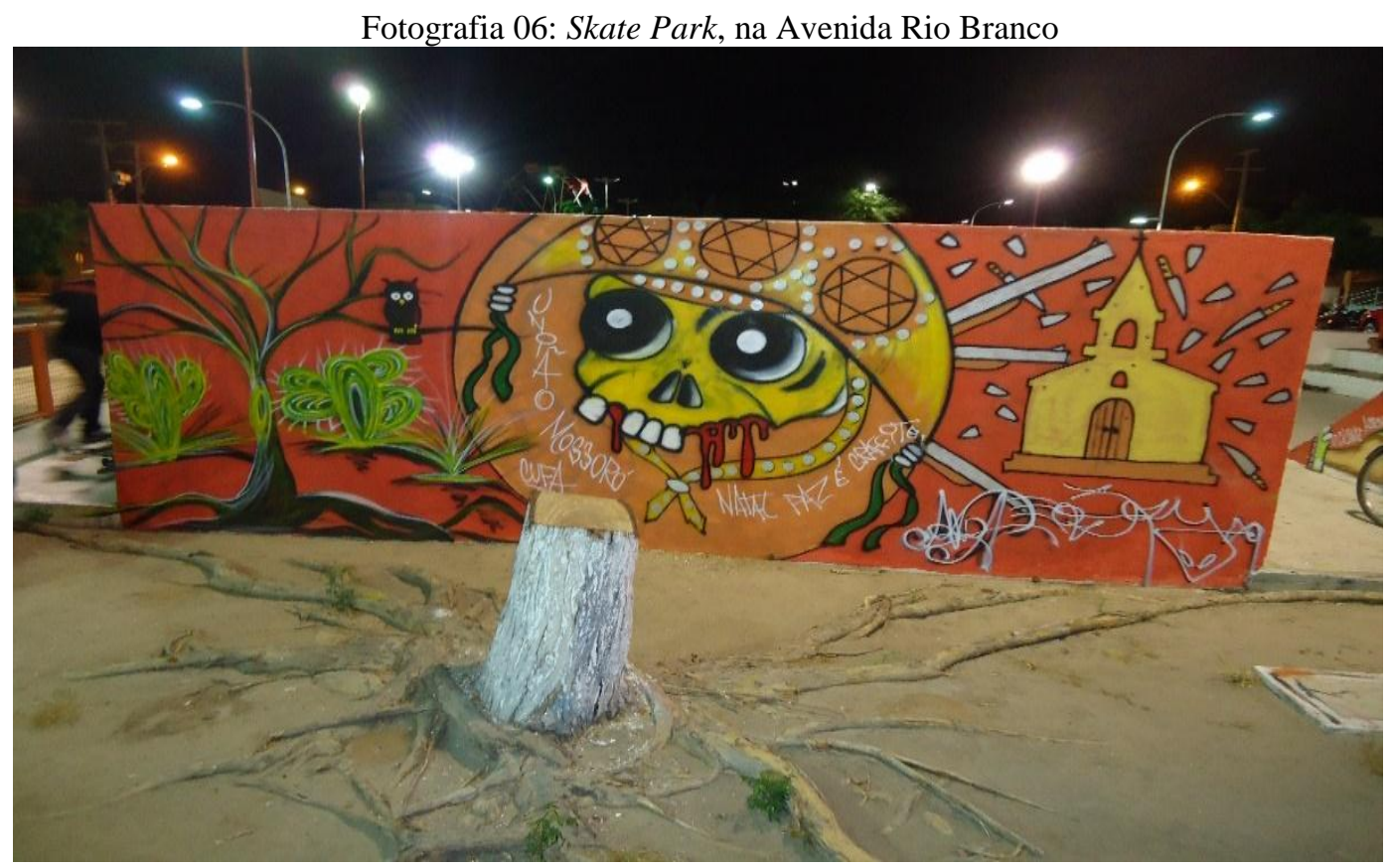

Foto: Edgley Freire Tavares

Fotografia 07: Skate Park, na Avenida Rio Branco 


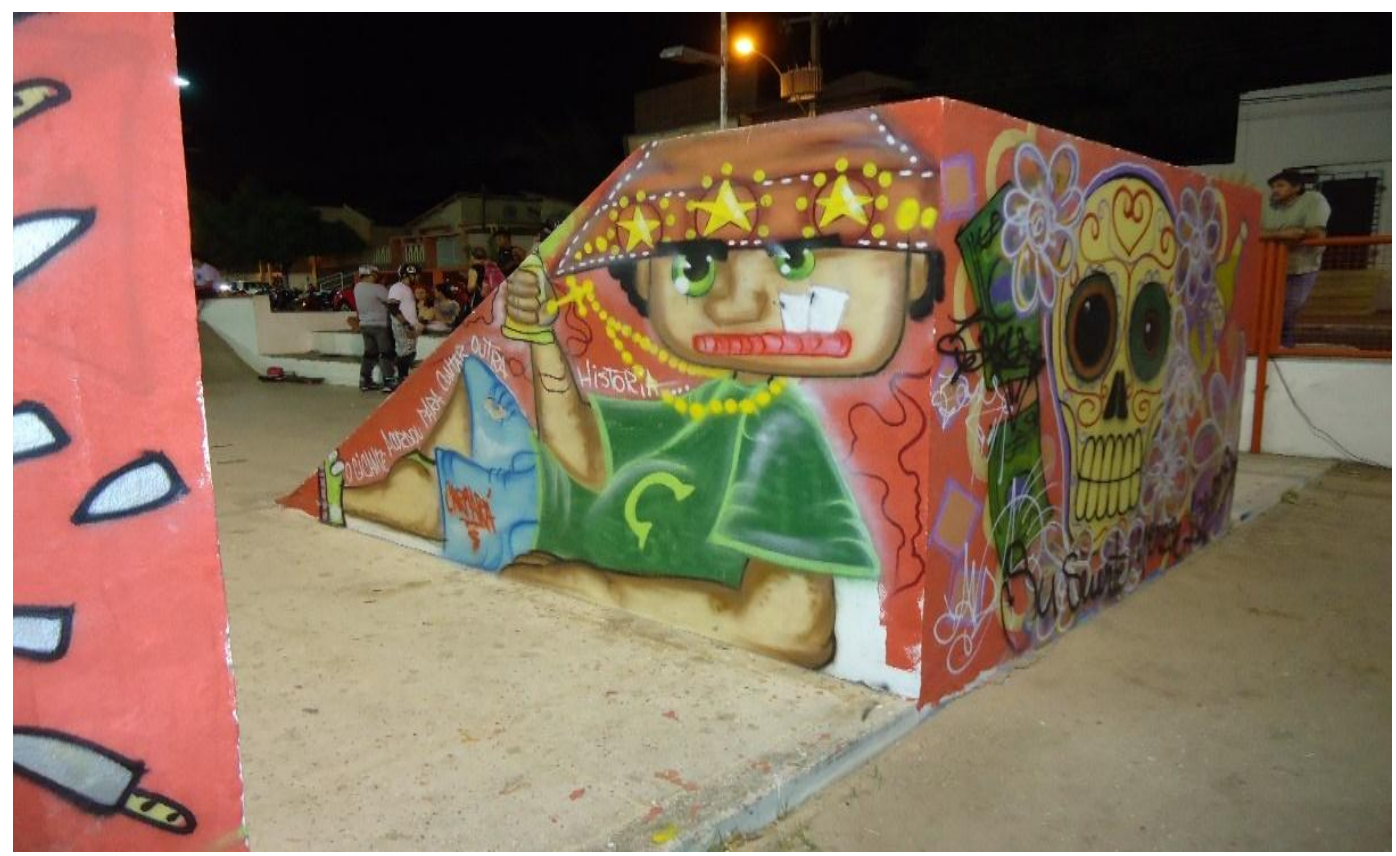

Foto: Edgley Freire Tavares

Estes dois grafites mostram o modo como a memória da resistência se desloca no decurso da história, transformando-se a partir de outros acúmulos enunciativos e outros atravessamentos simbólicos. Mesmo estando localizada no centro da cidade, a Skate Park configura-se como uma espécie de heterotopia, definida por Foucault (2006, p.415), como "lugares reais, lugares efetivos, lugares que são delineados na própria instituição da sociedade, e que são espécies de contraposicionamentos", espaço em que certos posicionamentos em relação à cultura podem ser, ao mesmo tempo, representados, contestados e invertidos, "espécies de lugares que estão fora de todos os lugares, embora eles sejam efetivamente localizáveis”. (FOUCAULT, 2006, p.415).

Espaço outro porque o grafiteiro atualiza de outro modo a memória da Resistência mossoroense ao ataque do bando de Lampião. Tal aspecto se apreende no plano da expressão do artista que retoma os significantes ou temas próprios da narrativa da resistência e os desloca numa outra semântica, da inversão e da ruptura. Como é possível ver, estas inscrições urbanas retomam já ditos nesta formação discursiva, como a imagem de uma igreja que neste contexto representa a igreja de São Vicente, mas a conjuga com outras simbologias. No primeiro dos dois grafites reproduzidos, alguns significantes chamam a atenção: a coruja e a caveira, sobretudo, por estarem normalmente relacionadas com a simbologia da morte. A arte da praça dos skatistas ativa nossa memória social, fazendo-nos associar a simbologia da morte com a memória da resistência mossoroense, tensão que se marca em indícios como a igreja, os punhais e as balas no entorno da arte, ou na própria ornamentação da caveira. O grafite materializa no plano estético um efeito de ruptura, ressaltado nessa associação interdiscursiva com a simbologia da morte. Como sabemos, os significantes da arte não estão postos de forma aleatória, muito pelo contrário, e o que lemos nos grafites é um cenário para uma outra narrativa. É desta forma que faz sentido a coruja, animal noturno que, assim como abutres, serpentes e corvos, alimenta-se de cadáveres e comumente aparece em representações da morte, quase sempre num cenário assustador, que o artista retoma e singulariza. E, nitidamente, esse significado se reforça no modo como o artista faz retornar a iconografia do cangaceiro, na forma de uma caveira, possibilitando outras associações e um deslize da memória recorrente na cidade. 
Entre os seus significados, a morte representa ou o fim de um ciclo, podendo nisso estar relacionada a elementos como a escuridão e a noite, ou também, como acontece em outras culturas, associar-se à ideia de recomeço, não como um fim em si, mas como uma transformação ou mudança, representando o início de um novo ciclo. $\mathrm{O}$ artista parece estar sensível a estas simbologias ao inverter a memória da resistência. Assim, ele parece criticar a remanência e a centralidade do culto à resistência, pois como é possível ler pela cidade, a atualidade dessa estratégia memorialista torna possível a vivacidade do morto, o que torna possível que o cangaceiro só exista enquanto mito, enquanto discurso. No primeiro dos grafites reproduzidos, esse jogo entre retomada e inversão se dá no modo singular com que o artista reproduz a iconografia do cangaceiro, mostrando-o enquanto uma caveira ornamentada com o tradicional chapéu de abas, característico da estética do cangaço, sujo de sangue e envolto na simbologia da morte, o que desestabiliza a memória e os sentidos.

Notemos que há uma coesão nas artes perfiladas na praça e o artista arremata seu contra discurso ao representar, no segundo grafite, um personagem usando camiseta, bermuda e tênis, trajes geralmente usados pelos skatistas, compondo ainda esse traje o mesmo típico chapéu de pontas adornado. Somado a estes indícios e ao fato de projetar-se na parede posterior outra caveira, lemos no segundo grafite o enunciado: "O gigante acordou para contar outra história...”. Nesta modalidade enunciativa que é o grafite, inscreve-se algo como a contestação de uma ritualização da memória, como se o grafiteiro insinuasse a morte de uma celebração: o cangaceiro está morto, viremos a página, contemos outra história.

\section{Considerações da análise}

$\mathrm{Na}$ análise dessas materialidades urbanas na formação do discurso da resistência, em sua gênese e dispersão, a arqueogenealogia aqui empreendida apontou, enquanto próprio do funcionamento histórico e semiológico dessa discursividade, certos jogos de memória entre o retorno e a mudança, tensão entre a paráfrase e a polissemia. Na ordem do discurso urbano, vimos que a memória da resistência mossoroense é gestada, controlada e que pesa sobre as formas de sua atualização uma série de táticas e modalizações enunciativas. Nestes termos, a arqueogenealogia da cidade em seu funcionamento semiológico evidenciou atravessamentos, acúmulos, deslocamentos e redefinições. Conforme pontua Nora (1993), a contemporaneidade dos estudos historiográficos marca a passagem de uma reflexão que buscava a história na continuidade de uma memória para a constatação de que a memória se projeta na descontinuidade de uma história. Pensando com o autor, diremos que a memória da resistência é uma fabulação do passado só possível nas derivas do tempo e nos deslizes do sentido, já que "a alucinação artificial do passado só é precisamente concebível num regime de descontinuidade" (NORA, 1993, p.19).

As descontinuidades, como vimos, estão materializadas em vários espaços da cidade. $\mathrm{Na}$ análise, buscamos apreender uma unidade nesse discurso urbano só possível na dispersão, na heterogeneidade das formas de atualização da memória, nas várias funções e efeitos de sentido dessa mitologia, possíveis pela cidade. Quanto ao aspecto metodológico, na descrição desta paisagem semiológica mossoroense, selecionamos materialidades urbanas que representassem a atualidade do funcionamento histórico e semiológico da discursividade da resistência, como forma de problematizar, como indicamos na introdução, o modo como as materialidades urbanas atualizavam a memória da resistência ao ataque de Lampião. Materialidades que fossem representativas, portanto, tanto das remanências e permanências, quanto das ampliações, transformações, deslocamentos e rupturas, inerentes ao funcionamento histórico e semiológico do discurso. Em específico, a 
análise incidiu sobre certas regularidades discursivas, no sentido foucaultiano do termo, enquanto aquilo que retorna diferentemente entre o visível e o enunciável de dada época (FOUCAULT, 2007).

Para este autor, a análise dos discursos implica a descrição de como os enunciados se correlacionam em torno de um mesmo tema ou de semelhantes objetos de discurso, nas tensões e limites de uma formação discursiva. Tais correlações, em termos de regularidades, são como espécies de aproximações e diferenças que mantém entre si as modalidades enunciativas numa formação discursiva. As modalidades de inscrição do acontecimento da resistência no espaço urbano se definem por meio de regras sociais, políticas, econômicas e estéticas diversas, pois vimos que tanto a repetibilidade de uma memória oficial da resistência quanto as rupturas em relação à memória só são possíveis devido a certas injunções históricas e a certos desejos inerentes aos lugares enunciativos descritos.

Entre a regularidade e a dispersão dos enunciados, a exemplo das materialidades urbanas aqui mostradas, a descrição arqueogenealógica não deve perder de vista que o funcionamento de uma discursividade é histórico, está sempre em devir, deslizando nas nuances do tempo. É desta forma que tentamos mostrar os pontos de aproximação e as diferenças no modo como as materialidades urbanas atualizam uma estrutura temática legitimada na cidade, desde a década de 1950 e que produziu, em termos ufanistas e épicos, o acontecimento da passagem de Lampião pelo município, no ano de 1927, fazendo desta memória da resistência e da vitória desta cidade sobre o cangaço, uma espécie de manancial de sentidos, algo como uma tradição, por meio da qual vemos facilmente girar um conjunto de práticas na cultura local.

$\mathrm{Na}$ paisagem desta cidade, materializa-se uma dupla ordem no funcionamento histórico e semiológico dos enunciados. Ao passo que os enunciados materializam a memória da resistência, em suas especificidades geográficas e simbólicas, funções e sentidos, a própria espacialidade é alterada pelas formas do enunciável, mudando-se a própria configuração urbana, fazendo da cidade de Mossoró uma espacialidade associada à memória da resistência. Em cada sítio de significação vimos uma tensão singular entre o retorno e o deslize da memória, diferenças que marcam a própria forma como os espaços se distribuem nessa geografia dos sentidos da resistência. Assim, o Memorial da Resistência Mossoroense é um monumento que recorda, especificamente, legitimando uma escrita oficial que vangloria os líderes políticos, religiosos e da economia da época, forma de lembrar que busca produzir sinonímias entre o passado e o presente. Isso porque em outros enunciados que se inscrevem pelo Memorial, não só no painel aqui analisado, os líderes políticos e grupos econômicos da atualidade são nomeados como espécie de guardiões da cidade, de suas tradições e conquistas, denotando os interesses em jogo na ordem discursiva memorialista. Nesta escrita oficial da memória, sintetizada no painel do memorial, uma imagética do cangaço é produzida na representação dos cangaceiros enquanto bandidos que tiveram por algozes os mossoroenses. E mesmo assim, a representação do cangaceiro bandido, caso de polícia, desliza, como foi possível ver em outros sítios de significação na cidade.

É assim que em outros espaços, outras materialidades inscrevem a contradição no interior da formação discursiva da resistência. É isso que possibilita à tematização do cangaceiro bandido deslizar, flutuar e seguir outros cursos, inclusive impor sua centralidade, algo possível numa cultura do turismo de eventos que faz do cangaceiro espécie de suvenir da cidade, marionete no discurso turístico e de promoção da cidade. A própria memória hegemônica da resistência, de seus temas e objetos fundantes se desloca, como foi possível notar na praça dos skatistas, na expressão do grafite. As artes mostradas 
da Skate Park são como enunciados que inscrevem rupturas na memória e questionam os sentidos cristalizados pelo viés historicista da escrita dos memorialistas. Nesse sentido, a análise arqueogenealógica leva em conta a contradição como princípio do funcionamento histórico e semiológico do discurso, pois o discurso é o caminho de uma contradição à outra, lugar de dispersões, de mutações e de mudanças. E tal qual Barthes (2001), que nos inspira a uma semiologia da cidade, a observação e a descrição dos signos pela cidade de Mossoró, enquanto espacialidade de sentidos, possibilitaram compreender a singularidade do modo como as materialidades discursivas urbanas inscrevem e significam o acontecimento da resistência mossoroense ao ataque de Lampião, nos deslizes da memória e dos sentidos.

\section{Referências}

ALBUQUERQUE JR., Durval Muniz de. A invenção do Nordeste e outras artes. São Paulo: Cortez, 2011.

ALBUQUERQUE JR., Durval Muniz de. A feira dos mitos: fabricação do folclore e da cultura popular (Nordeste 1920-1950). São Paulo: Intermeios, 2013.

BARTHES, Roland. A câmara clara: nota sobre a fotografia. Tradução de Júlio Castañon Guimarães. Rio de Janeiro: Nova Fronteira, 1984.

BARTHES, Roland. A aventura semiológica. Tradução de Mário Laranjeira. São Paulo: Martins Fontes, 2001.

BARTHES, Roland. Mitologias. Tradução de Rita Buongermino e Pedro de Souza. Rio de Janeiro: Bertrand Brasil, 2011.

CERTEAU, Michel de. A cultura no plural. Tradução de Enid Abreu Dobránszky. Campinas/SP: Papirus, 1995.

DELEUZE, Gilles. Foucault. Tradução de Claudia Sant' Anna Martins. São Paulo: Brasiliense, 2005.

FELIPE, José Lacerda Alves. A (re)invenção do lugar: Os Rosados e o "país de Mossoró". João Pessoa/PB: Grafset, 2001.

FERNANDES, Raul. A marcha de Lampião: assalto a Mossoró. Mossoró: Fundação Vingt-un Rosado/ Coleção Mossoroense, 2007.

FOUCAULT, Michel. Outros espaços. In: Estética: literatura e pintura, música e cinema (Ditos \& escritos III). Tradução de Elisa Monteiro. Rio de Janeiro: Forense universitária, 2006. P.411-422.

FOUCAULT, Michel. A arqueologia do saber. Tradução de Luiz Felipe Baeta Neves. Rio de Janeiro: Forense Universitária, 2007.

FOUCAULT, Michel. A ordem do discurso. Tradução de Laura Fraga de Almeida Sampaio. São Paulo: Loyola, 2009.

GEERTZ, Clifford. A interpretação das culturas. Rio de Janeiro: LTC, 2008.

GINZBURG, Carlo. Sinais: raízes de um paradigma indiciário. In: Mitos, emblemas, sinais: morfologia e história. Tradução de Frederico Carotti. São Paulo: Companhia das letras, 1989. P.143-179. 
GREGOLIN, M. do R. Análise do discurso e semiologia: enfrentando discursividades contemporâneas. In: SARGENTINI, V.; CURCINO, L.; PIOVEZANI, C. (orgs.). Discurso, semiologia e história. São Carlos/SP: Claraluz, 2011. p.83-106.

HALL, Stuart. A centralidade da cultura: notas sobre as revoluções culturais do nosso tempo. Educação \& Realidade, Porto Alegre, v. 22, n. 2, p. 15-46, jul./dez. 1997.

NONATO, Raimundo. Lampião em Mossoró. Mossoró: Fundação Vingt-un Rosado/Coleção Mossoroense, 2011.

NORA, Pierre. Entre memória e História. A problemática dos lugares. Projeto História. Tradução de Yara Aun Khoury. Vol.10, São Paulo, dez. 1993. p.07-28.

ORLANDI, Eni Puccinelli. A cidade dos sentidos. Campinas: Pontes, 2004.

ORLANDI, Eni Puccinelli. A cidade como espaço político-simbólico: textualização e sentido público. In:

Campinas: Pontes, 2008.

Discurso e texto: formulação e circulação dos sentidos.

PÊCHEUX, Michel. Discurso: estrutura ou acontecimento. Tradução de Eni Orlandi. Campinas/SP: Pontes, 2008.

PÊCHEUX, Michel. Leitura e memória: projeto de pesquisa. In: Análise de Discurso: Michel Pêcheux. Tradução de Eni Orlandi. Campinas/SP: Pontes editores, 2011. p.141-150.

POLLAK, Michel. Memória, esquecimento, silêncio. Tradução de Dora Rocha Flaksman. Estudos históricos. Rio de Janeiro, v.2, n.3, p.3-15, 1989.

RAGO, Margareth. O efeito-Foucault na historiografia brasileira. Tempo Social; Rev. Sociol. USP, S. Paulo, 7(1-2): 67-82, 1995.

SARGENTINI, V. Contribuições da semiologia histórica à análise do discurso. IN: SARGENTINI, V.; CURCINO, L.; PIOVEZANI, C. (orgs.). Discurso, semiologia e história. São Carlos/SP: Claraluz, 2011. p.107-126.

SILVA, Lemuel Rodrigues da. Os Rosados encenam: estratégias e instrumentos da consolidação do mando. Mossoró: Queima Bucha, 2004.

TAVARES, Edgley Freire; SILVA, Francisco Paulo da. A inscrição da memória no espaço urbano: efeitos de sentido na contação da invasão de lampião a Mossoró feita monumento. IN: MILANEZ, Nilton; SANTOS, Janaina de Jesus. (org.). Análise do discurso: sujeito, lugares e olhares. São Carlos: Claraluz, 2009. p.23-30 